THE RELATION OF DENTITION TO DIS. EASES OF THE ALIMENTARY 'TRAC'T.

AF'TER careful observation and study of the diseases of infants during the period of dentition, Dr. Adams never accepts either the evolution or the eruption of the teeth as an etiological factor in ans of them. He would not be dogmatic in the assertion that dentition is never a cause of disease, but such, indeed, has been his experience in pediatrics. If those interested in this subject will pursue an investigation they will eventually conclude that improper alimentation and not "teething" is the most potent factor in causing the disorders of the alimentary tracts of infants. The best way to overcome the influence of the superstition is by emphasizing in our colleges the fact that dentition is a pliysiological process, that after-coming graduates may assist us in convincing mothers that the observance of the strictest regimen and diet during the period of dentition is the surest guarantee against teething disorders.-Archives of Pediatrics, Sep. 1889. Occidental Medical Times. Dec. 1889.

\section{TREATMENT OF OBESITY.}

Frequentry the practising physician is called upon to treat obesity in women where this morbid condition constitutes a most tiresome infirmity, and is often a complication of most of the affections of the femiuine sex. We advise a faithful trial of the method of Schwenninger and Oertel, which has given so many excellent results in Germany. The following are the indications which have been laid down by these savants :

1. Elevate the tone of the muscular force of the heart.

2. Maintain the normal composition of the blood.

3. Regulate the quantity of liquid in the economy.

4. Prevent the deposit of fat.

The above indications are observed by the following methorls :

1. The cardiac muscle is increased in tone by the augmentation of physical exercise-for ex. ample, by ascending elevations. It is necessary to progress with caution; the exercise will be gradual and the amount of work proportionate to the resistance of the subject.

2. To maintain the normal composition of the blood it is necessary that the alimentation should be principally albuminous; it will consist of the lean of beef, roast or boiled, veal, mutton, game and eggs.

We can add green vegetables, such as cabbage and spinach, but fat and hydrocarbons shall be given only in small doses-for example, the nmount of bread should not exceed 120 to 180 grammes a day.

3. We should limit each day the quantity of drink-180 grammes of coffee, of tea, or milk;
360 grammes of wine; 240 to 480 grammes of water will complete the amount of liquid absorbed in the twenty-four hours. Beer is entirely forbidden. Then, again, transpiration is excited by energetic exercise as well as by baths and coverings.

4. Listly, the deposit of fat is attacked by the practice of the above-mentioned principles of dietetics.

This, for example, is how we should proceed : Mornin.g-The cup of tea or cotfee, with a little milk, will represent a total of about 180 grammes, and about 90 grammes of bread.

Noon.-From 80 to 100 grammes of soup, 210 to 240 grammes of beef, roast or boiled, veal, game, salud or vegetable, a little fish if desired, but cooked without fat, 30 grammes of bread or farinaceous pudding (never more than 90 grammes), 90 to 180 grammes of fruit in season, for dessert. It is preferable not to drink at the repast, but in hot weather we can allow from 180 to 240 grammes of a light wine.

Afternoon.-The same quantity of tea or coffee as in the morning, with, as a maximum, 180 grammes of water and $30 \mathrm{grammes}$ of bread as an exceptional concession.

Evening.-One or two boiled eggs, 30 grammes of bread, perhaps a little slice of cheese, salad, and fruits; 180 to 240 grammes of wine, with 120 to 150 grammes of water--Revue de Therapeutique. The Times and Repoter, Nov. 23, 1889.

\section{CEREBRAL LOCALISATION IN ITS PRAC- TICAL RELATIONS.}

Prof. Ferrier having given a brief resumé of our present knowledge of the localising symtoms of cerebal lesions, refers to the relative danger of operating for their relief. He finds the total mortality for operations upon the brain (including the cerebellum) to be certainly below 30 per cent., which compares favourably with that of other major operations universally regarded as legitimate. As to the indications for operation upon the brain, he lays down the following rules:-(1) We should operate in all primary cranial injuries with symptoms of compression or localised paralysis or convulsions. (2) Abscesses of the brain, whether traumatic or otherwise, should certainly be evacuated. (3) Of secondary trephining for traumatic epilepsy he takes a somewhat unfavourable view. The majority of cases of this nature recorded as cured have not been under observation for periods sufficiently long to permit of such a conclusion, and, allowing at least a sear to elapse before pronouncing the results satisfactory, lie reduces the cures to $14.6 \mathrm{per}$ cent. Hence he would reject operation for epilepsy unless there be, besides the mere history of a blow, clear objective evilence of local injury. 
He also strongly advocates free excision of the focal centre affected in these cases. In old cases he believes the probabilities of a cure to be diminished by the establishment of an "epileptiform habit' either in the opposite hemisphere or in a lower centre. (4) In all cases of cerebral tumour he advocates operation at as early a period as possible, even if it be exploratory only.-Brain, July, I889. Medieal Chronicle, Dec. 1889.

\section{Trantsattions of althedital Soutidtits.}

THE CALCUTTA MEDICAL SOCIETY.

A meeting was held at the Medical College on Wednesday, 18th December 1889. The President, Dr. Lall Madhub MookerJee, in the chair.

Dr. J. B. Gibbons showed a liver and spleen which had been removed from a fatal case, Assam fever, probably the Kala-azar which has been for some years attracting attention in the Garo Hills,

The following are notes of the case:-

Sainburan, aged about twenty years, a native of Assam, was admitted into the 1st Physician's Ward on the 9 th November and died on 12 th December 1889.

$\mathrm{He}$ stated that he had been suffering from Assam fever for about a year. On admission his condition was as follows:-very emaciated and weak; complexion, sallow conjunctiva yellow; liver extended about $2 \frac{1}{4}$ inches below the costal arch, spleen enlarged. His temperature on the evening of the day of admission was $101^{\circ} 6$ Faht.; pulse weak.

Fever continued until the 25 th November, the temperature ranging from normal to $101^{\circ} \mathrm{F}$ aht. the evening temperature being generally about $101^{\circ}$ Faht., while on the morning it was lower and some days normal. From the 25 th to 28 th he was free from fever.

On the 29 th rise of temperature occurred and slight fever was present to the $3 \mathrm{rd}$ of December, when the temperature went up to $104^{\circ}$ Faht. and from this date to his death the fever ranged from $100^{\circ}$ Faht. in the morning to $104^{\circ}$ in the evening, and on one occasion reached $105^{\circ}$ Faht.

The bowels were constipated during the first fortnight after admission, requiring repeated doses of aperients to procure an evacuation. On the $7 \mathrm{th}$ December mucus and blood appeared in the stools, and from this date he passed several loose bilious stools, containing a small quantity of blood.

He gradually became weaker and died at 9 A.M. on the 12 th December 1889.

Abstract of post-mortem notes. The examination was made 6 hours after death. Body very emaciated, no subcutaneous fat, no œdema, the peritoneal cavity contained about 16 ozs. of serous fluid.

The liver was large, weight 3lbs. 3ozs., mottled dark green and yellow, much congested. Microscopical examination shows great congestion of all the lobular capillaries, but most marked in those belonging to the central vein. The hepatic cells are small, shrunken, granular, and contain minute masses of brown pigment. In some lobules the hepatic cells are completely destroyed, all that remains being an amorphous granular mass; the destruction of the hepatic cells is the most striking feature, the fibrous framework is unaltered. The spleen is large, weight $1 \frac{1}{2} \mathrm{lbs}$. and soft and friable, of a brownish red colour sections, shows extreme congestion but no pigmentation.

The kidneys are slightly enlarged, the cortex is pale streaked with red, the medulla of a dark red colour, weight of each $4 \frac{1}{2}$ ozs.; microscopical examination, extreme congestion, the renal epithelium is granular and disintegrating, many of the tubules contain masses of broken down epithelium.

The mucous membrane of the small intestine was bile stained in the upper portion; Peyer's patches were healthy.

The membrane of the whole of the large intestine was thickened and presented innumerable small shallow ulcers, some recent others of long standing. No worms in the intestines.

The muscle substance of the heart pale and flabby.

Remarks. -The course and symptoms in this case point to the probability of its being an example of Kala-azar. The patient was an Assamese and only came to Calcutta a short time before he was admitted into hospital. He suffered from enlargement of the lever, spleen, and anæmia recurring, attacks of fever and dysentery. These are the prominent symptoms in cases of $K_{a} l_{a-}$ azar vide "Indian Medical Gazette," June 1889, pp. 188-189. Of the post mortem appearances, the absence of pigment in the spleen is noticeable. In all cases of long continued malarial poisoning in Lower Bengal the spleen contains large quantities of pigment.

In the liver the destruction of the hepatic cells is greater than $I$ have found in any case of: malaria in Bengal.

Dr. McLeod showed the following specimens :-

1. SAC OF AN OLD REDUCIBLE HERNIA OPERATED ON FOR RADICAL CURE FOR THE SECOND TIME.

Synopsis of the case.

Kuman Ali, Mahomedan male, æt. 40, a khalasi by occupation. The gut commenced to descend on the right side three years and two months ago. Two years and five months ago he came to this hespital and was operated on for radical 